\title{
Intra-Atrial Conduction Delay by ECG
}

\section{Finding}

National Cancer Institute

\section{Source}

National Cancer Institute. Intra-Atrial Conduction Delay by ECG Finding. NCI Thesaurus.

Code C71073.

An electrocardiographic finding of a delay in impulse propagation through the atria. This

is characterized by broad P waves which are often biphasic in V1. (CDISC) 